\title{
Produção de jogo analógico como estratégia de aprendizagem e ensino na pós-graduação em Design: o Jogo da Vida Acadêmica
}

\author{
Analog game production as a strategy for learning and teaching in the postgraduate \\ in Design: The Academic Life Game
}

\author{
DIAS, Cynthia Macedo; Mestrado em Design; Pontifícia Universidade Católica do Rio de Janeiro \\ cymadi@gmail.com
}
SABOIA, Patricia Rocha; Doutorado em Design; Pontifícia Universidade Católica do Rio de Janeiro psaboia@gbl.com.br

XAVIER, Guilherme; Doutorado em Design; Pontifícia Universidade Católica do Rio de Janeiro

guix@puc-rio.br

\begin{abstract}
Resumo
O uso de jogos em situações de ensino formal demanda entendimentos e práticas, cujos resultados dependem tanto dos conceitos e contextos envolvidos quanto da experiência de seus produtores. Ao reconhecermos quem joga como criador e desenvolvedor, além de interator, operam-se métodos e processos de construção de conhecimentos, para transformar conteúdos em regras. O Jogo da Vida Acadêmica foi elaborado por estudantes de pós-graduação em Design para provocar uma experiência dos desafios vivenciados em um curso de doutorado e estimular a consideração desse trajeto de forma interdisciplinar. O presente artigo discute o jogo enquanto abordagem de aprendizagem e ensino na pós-graduação em Design, o projeto do jogo em questão, sua realização e os métodos e processos desenvolvidos. O jogo de tabuleiro apresenta-se como representação sintética e sistemática de conceitos e relações e promove problematizações coletivas das "regras" vivenciadas, abrindo espaços para a rediscussão do cotidiano acadêmico.
\end{abstract}

Palavras Chave: jogos; metodologia; ensino-aprendizagem.

\begin{abstract}
The use of games in situations of formal education demands understandings and practices, whose results depend as much on the concepts and contexts involved as on the experience of its producers. When we recognize who plays as creator and developer, in addition to interacting, we operate methods and processes of knowledge construction, in order to turn content into rules. The Academic Life Game was developed by graduate students in Design to provoke an experience of the challenges experienced in a doctorate course and stimulate the consideration of this path in an interdisciplinary way. This article discusses the game as an approach to learning and teaching in the postgraduate in Design, the project of the game in question, its accomplishment and the methods and processes developed. The board game presents itself as a synthetic and systematic representation of concepts and relationships and promotes collective problematizations of the lived "rules", opening spaces for the re-discussion of academic everyday life.
\end{abstract}

Keywords: games; methodology; learning and teaching. 


\section{Introdução}

No Design, como campo de conhecimento de natureza tecnológica, interdisciplinaridade é vocação (COUTO, 1997, p.66). De forma ampla, entende-se como interdisciplinares práticas constituídas baseadas na relação estrutural de disciplinas envolvidas, nas quais pretende-se uma finalidade no fluxo de intercâmbios, capazes de construir conhecimentos mútuos. Assim, "interdisciplinaridade poderia ser considerada como princípio de organização ou de estruturação de conhecimentos, capaz de modificar os postulados, os conceitos, as fronteiras, os pontos de junção e os métodos das disciplinas envolvidas" (COUTO, 1997, p.30). Diferente da multidisciplinaridade, há na interdisciplinaridade pretensões de nivelação hierárquica a guisa de uma realização científica entre conhecimentos de origens distintas.

$\mathrm{Na}$ formação em Design, o reconhecimento da importância de um pensamento interdisciplinar deve ser cultivado, especialmente naquilo que Fazenda (2001,p.22) considera condição maior: um profundo sentimento de parceria. No curso de pós-graduação em Design da PUC-Rio, a interdisciplinaridade é fomentada para se estabelecer uma noção de reciprocidade ou co-propriedade, permitindo diálogos entre os participantes e estabelecendo intersubjetividade, característica essencial para reflexão.

Com propriedades integradoras semelhantes, jogos são mídias expressivas que demandam conhecimentos de diferentes fontes para um resultado adequado no que se propõem enquanto sistemas de fins e propósitos. Tal perspectiva o coloca em evidente importância ao se tratar assuntos por meio da interdisciplinaridade, uma vez que, na reunião de conteúdos por regras e procedimentos, permitem articulações interpessoais baseadas nas obtenção e trocas de experiências por parte dos seus jogadores. Além destes, considerando a prática de design de jogos (game design) como uma especificidade do Design enquanto área de conhecimento e apresentando as mesmas discussões científicas, filosóficas e técnicas, seus produtores gozam de oportunidade de planejar e operar símbolos e discursos.

Jogos podem ser considerados enquanto gêneros discursivos, ações retóricas tipificadas, na perspectiva dos Estudos da Linguagem. Nesse sentido, são compostos de elementos configurados em sistemas, que mediam a interação humana e participam na construção de sentidos sociais. $O$ gênero discursivo tem o potencial de estruturar a ação social, por mediar o público e o privado, o indivíduo e a comunidade (CARVALHO, 2005). Assim, os jogos mediam a construção de relações sociais, de identidades e de saberes sobre o mundo, e carregam sentidos sobre esses processos, materializados não só no uso da linguagem verbal, como também da visual, da retórica procedimental (presente nas regras) e de outros elementos. Além disso, todo jogo, como texto (composto de elementos verbais, visuais e procedimentais - as regras), já é constitutivamente dialógico, pois carrega em si diferentes discursos que o precedem na cultura e que o compõem, enquanto objeto de linguagem - assim como enquanto objeto de design.

O presente artigo discute a elaboração e aplicação de um jogo de tabuleiro enquanto estratégia de aprendizagem e de ensino na pós-graduação em Design. Descrevemos o projeto do jogo em questão, sua realização e os métodos e processos desenvolvidos. A discussão dos fundamentos e do processo de elaboração do jogo tem como objetivo disponibilizar elementos para o desenvolvimento de experiências semelhantes em cursos de graduação e pós-graduação. 


\section{Contexto}

A pós-graduação em Design da PUC-Rio apresenta a área de concentração "Design e Sociedade", que:

engloba estudos sobre os múltiplos aspectos e as várias interfaces do Design com a Tecnologia, a Arte, as Ciências Humanas e Sociais, com destaque para as influências recebidas e as conseqüências da prática do designer para a cultura, a sociedade e o meio ambiente, tendo por fio condutor a investigação de suas relações com os usuários e com o processo produtivo. (DAD, 2017).

A carga horária mínima para o mestrado é de 24 créditos ( 8 disciplinas de 3 créditos), incluindo disciplinas obrigatórias e eletivas e estágio docente (obrigatório apenas para alunos com bolsa positiva). Para o doutorado, essa carga é de 48 créditos (aproveitando-se 24 créditos do mestrado em bloco). As eletivas oferecidas tratam de temas variados, de acordo com as linhas de pesquisa do programa e as pesquisas que vêm sendo desenvolvidas pelos professores.

O jogo foi desenvolvido como seminário final da disciplina "Produção Interdisciplinar de Texto" no primeiro período de 2012, no curso de Pós-Graduação em Design da PUC-Rio, oferecida pelas professoras doutoras Jackeline Lima Farbiarz e Rita Maria de Souza Couto. A ementa da disciplina "Produção Interdisciplinar de Texto" previa o desenvolvimento de um:

Espaço interdisciplinar de leitura e produção textual. Aprofundamento de estratégias de construção da tipologia textual acadêmica e de mecanismos de produção de sentidos. Visão dialética do texto na perspectiva da análise do discurso e da abordagem interacionista. (COUTO e FARBIARZ, 2012).

Os objetivos da disciplina buscavam:

Refletir sobre a leitura e a escrita em seus aspectos semânticos, nas relações entre linguagem e pensamento, quanto às funções de cada tipo de texto e suas condições de produção.

Auxiliar o aluno a tornar-se um leitor autônomo e um produtor competente de textos.

Favorecer a concepção de aluno como sujeito histórico da construção de sua linguagem. Levantar, analisar e produzir textos na temática Design e Educação. (idem).

A disciplina, de 3 horas semanais, envolveu duas turmas de seis alunos cada, com duas professoras dividindo o mesmo espaço físico e a condução das aulas. Procurando propiciar a coconstrução, as professoras desenvolveram uma metodologia baseada na discussão de textos, promoveram oficinas e apresentações sobre interdisciplinaridade e argumentação, abrindo então espaço para que as subjetividades entrassem em cena, propondo construções coletivas que recorriam às bagagens e repertórios de cada aluno.

Para a apresentação final da disciplina, as professoras solicitaram que estas fossem orais, para toda a turma, e que não se restringissem ao gênero "seminário", muito frequente nas aulas de pós-graduação. A fim de estimular a produção competente de textos (incluindo "práticas de ensino" como texto), de forma interdisciplinar, as apresentações de cada grupo deveriam incorporar a criatividade, explorar múltiplos suportes, envolver a turma em novas construções coletivas. A proposta colocava o desafio de ultrapassar as barreiras "disciplinares" das expectativas em relação ao que seria uma "disciplina" de pós-graduação e ao que seriam apresentações de trabalhos acadêmicos.

Como resultado, os alunos apresentaram propostas que envolviam construção de poesias, 
contos, apresentações que integravam texto, imagens, animação, oficinas de produção coletiva de "treliças" de frases entretecidas, entre outras. Pensando nas questões que trabalhamos ao longo do semestre, incluindo a discussão a respeito do que seria interdisciplinaridade e de como esta se manifesta no design, buscamos uma forma de fazer os colegas experimentarem a interdisciplinaridade na prática e refletirem sobre o lugar desta em nossas vidas.

A idéia de criar um jogo que simulasse a vida acadêmica surgiu de conversas entre as participantes do grupo, em que cada uma contava como escolhas ou situações que aconteceram em suas vidas as fizeram alterar o percurso previsto, e em como um curso de pós-graduação possibilita que possam ser trilhados caminhos diferentes, chegando ao mesmo "lugar": a conclusão de um curso stricto sensu. Partindo desse conceito de múltiplos caminhos e um ponto final em comum, decidimos desenvolver um jogo para experimentar, junto com a turma, algumas das infinitas possibilidades de caminhos que a escolha de um percurso acadêmico nos coloca, refletindo sobre os aprendizados e construções que podem surgir de cada um deles.

\section{Projetando o(s) percurso(s): o percurso de um projeto}

Como trataríamos do percurso de um curso de pós-graduação, iniciamos a geração de alternativas com a idéia de um jogo de "trilha", um tabuleiro que apresentava um caminho linear, que começava no processo seletivo. Para metaforizar as incertezas, haveria interferências à revelia do jogador, baseadas na sorte, por meio da rolagem de dados: dependendo de onde caísse, o jogador poderia ser reprovado em alguma etapa ou ter algum percalço que o fizesse voltar algumas casas, ou mesmo ao início do jogo.

Por ser completamente linear, nessa versão, o jogo não apresentava, ainda, alternativas de caminhos diferentes: limitava-se a um jogo de sorte ou azar, com casas de "Sorte ou Revés" que fariam o jogador andar para frente ou para trás, e onde a sorte nos dados e no sorteio das cartas definiria seu destino no jogo. Não havia possibilidades de estabelecimento de estratégia e tomada de decisão. Como a intenção era representar múltiplas possibilidades de caminhos e provocar a tomada de decisão perante o desconhecido, foi necessário gerar novas alternativas.

Com o auxílio do pesquisador e designer de jogos Guilherme Xavier, co-autor do presente artigo e, na ocasião, também aluno da pós-graduação em questão, pudemos obter conhecimentos acerca de princípios do Design de Jogos que permitiram o aprofundamento do conceito e o desenvolvimento satisfatório do projeto, além de nos colocar em uma situação interdisciplinar, na busca por novos conhecimentos na forma de uma parceria.

De fato, a intenção era incorporar estratégia, motivação e espírito de equipe, e não basearse somente na sorte. $\mathrm{O}$ jogo deveria buscar estimular a interdisciplinaridade ou a discussão sobre ela, possibilitar a escolha de atividades extra-curriculares (caminhos "alternativos") e a realização de parcerias com outros jogadores. Ao tentar transpor essas idéias para um tabuleiro, um esquema linear de idas e vindas baseadas na sorte não alcançava a metaforização pretendida.

Conforme afirma Bogost (2010), um jogo persuasivo é um modelo procedimental de alguma situação real, chamada por ele de "sistema-fonte". Entretanto, o "sistema-fonte" nunca existe enquanto tal, mas é definido no próprio processo de seleção e modelagem realizado pelos designers do jogo, a partir de sua subjetividade. Na interação com a simulação construída, as "(...) lacunas entre o modelo procedimental elaborado pelo designer a partir de um sistema-fonte e a subjetividade do jogador, suas preconcepções e sua compreensão existente daquela simulação" 
(BOGOST apud FULLERTON 2008, p.57, tradução nossa) estimulam o jogador a cotejar seus próprios modelos de mundo com o modelo proposto pelo jogo.

Fullerton (2008, p.49) aponta que certos elementos formam a estrutura dos jogos. Assim, jogadores, objetivos, recursos, procedimentos, conflitos, limites e resultados, dotam os jogos de sua essência e, sem os quais, jogos deixam de ser reconhecidos como tais.

Partindo desses pressupostos para definir nosso olhar sobre a jornada de um curso stricto sensu, estabelecemos que, além dos elementos formais, os elementos essenciais que compõem o "sistema" do percurso da pós-graduação seriam os conceitos de Tempo, Motivação e Conhecimento. Simplificando ao máximo, estabelecemos algumas inter-relações básicas entre esses "recursos", configurando as premissas que orientariam o jogo:

1. Quanto mais Tempo se investe, mais Conhecimento se pode obter; quanto menos Tempo, menos Conhecimento.

2. Quanto mais se investe em Conhecimento, menos Tempo se tem para investir em outras coisas, e vice-versa.

3. Quanto mais Motivação, melhor se consegue utilizar o Tempo para obter Conhecimento, e, quanto menos Motivação, menor o rendimento do Tempo em termos obtenção de Conhecimento.

4. A Motivação é algo que se pode perder ou ganhar, mas o Conhecimento é acumulado, nunca perdido.

A partir da definição das premissas, estabelecemos o tabuleiro como metáfora do tempo na vida acadêmica. Havia então o desafio de como realizar essa representação gráfica. Nossa questão condutora, neste momento da pesquisa, era: que "forma" teria um doutorado? Foram consideradas formas de árvore, pensando na multiplicidade de caminhos.

Entretanto, o formato circular, ou em espiral, foi ganhando pregnância, pelo fato de haver muitos "ciclos" no percurso acadêmico - inícios e términos de disciplinas, de semestres e de anos que, como estrutura, se repetem, embora o estudante não esteja mais no "mesmo lugar" em termos de conhecimento e de desenvolvimento das pesquisas. Com isso, para representar a passagem do aluno/jogador pelo tempo do curso, chamando atenção para a circularidade de vários "começos" e "finais" de semestre e de cada ano, consideramos então, tabuleiros circulares, divididos em anos ou semestres.

Os jogadores poderiam circular pelas casas do tabuleiro e haveria casas de Decisão, onde fariam escolhas relativas ao curso, e casas de "Sorte ou Revés" que os levariam "para trás" ou "para a frente". Optamos inicialmente por esta configuração e desenvolvemos então o tabuleiro 2. Porém, ele não incluía ainda a representação gráfica das disciplinas que deveriam ser feitas, e também não representava visualmente os diferentes caminhos trilhados a partir das decisões tomadas, mantendo a linearidade. Além disso, os fatores "Conhecimento" e "Motivação" ainda não estavam incorporados às mecânicas do jogo. 
Figura 1 - Primeira e segunda versões do tabuleiro
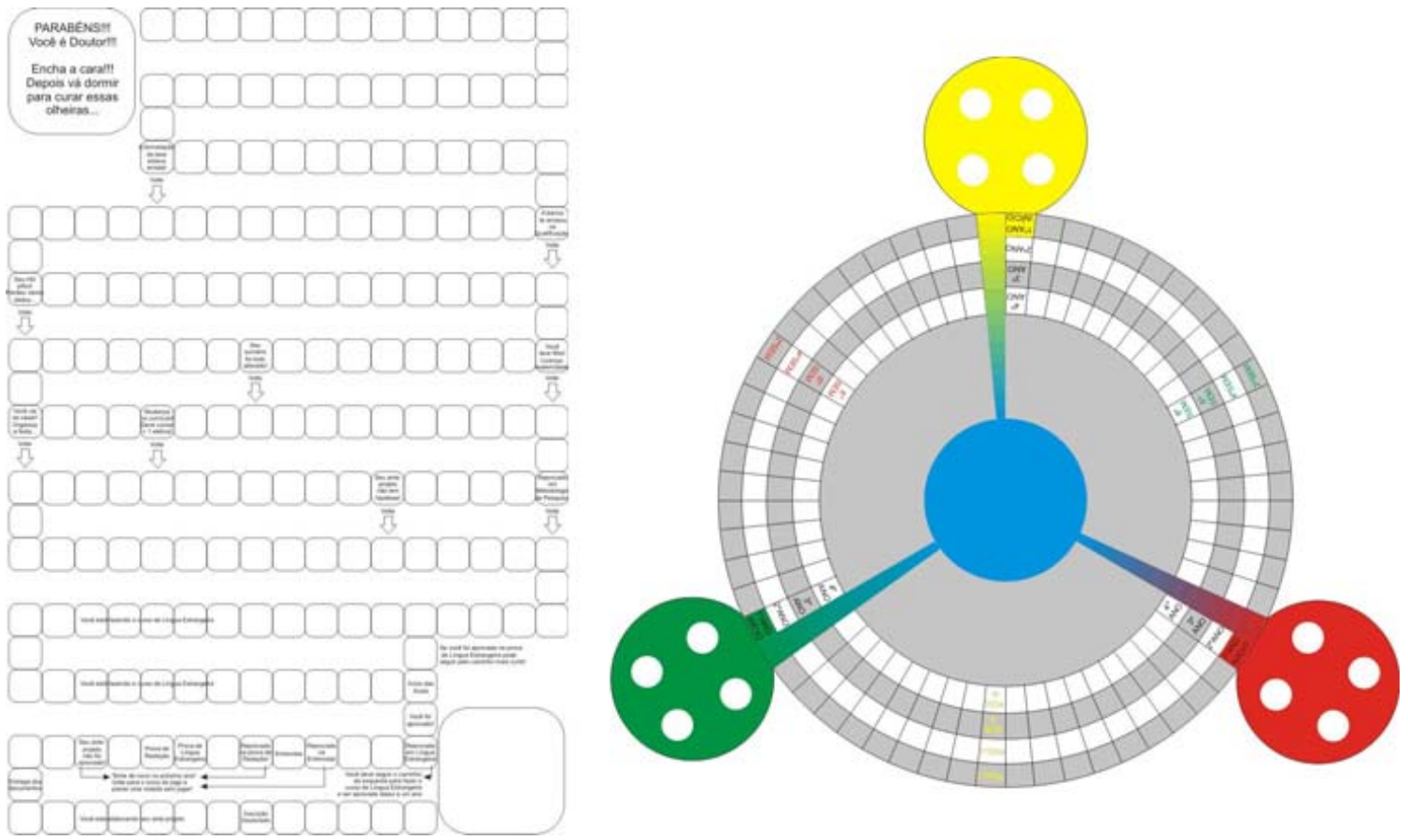

Fonte: Produzida pelos autores (2012)

Passamos então ao desenvolvimento do tabuleiro 3. Como solução para distinguir as disciplinas obrigatórias do curso, foram desenhados circuitos internos em cada um dos 8 semestres, que representam os 4 anos de doutorado, e estes foram dispostos em duas colunas, em que os jogadores passariam por cada semestre de forma sequencial. Embora a configuração em espiral tenha sido dispensada nessa alternativa, a circularidade foi mantida na representação das disciplinas e semestres.

Em cada semestre, o jogador teria a possibilidade de cursar até 4 disciplinas (considerando o tempo disponível, uma média do que é realizado por alunos de pós-graduação), sendo que cada cor correspondia a um tipo de disciplina, de acordo com a configuração do curso da PUC-Rio. Por exemplo: laranja, disciplina obrigatória; rosa, disciplina da linha de pesquisa do orientador; verde, disciplina eletiva fora do programa de pós-graduação em Design etc.

O fator "Conhecimento" foi incluído em forma de pontuações - as "Pedras do Conhecimento" - que o aluno ganharia quando fizesse atividades extra-curriculares ou interdisciplinares. O fator "Motivação", devido à já citada relação com o Tempo, seria representado pela "rapidez" com que o peão anda pelo tabuleiro: quando o jogador completasse alguma atividade extra-curricular ou interdisciplinar, o aumento da motivação faria com que, na rodada seguinte, ele andasse o dobro do número de casas tiradas no dado.

Entretanto, realizando um teste com dois jogadores, percebemos que as decisões ainda não geravam a abertura de novos "caminhos", e que as conclusões de disciplinas não envolviam qualquer tipo de "desafio", pois bastava tirar no dado o número necessário para ir adiante, o que fazia com que o jogo se tornasse muito rápido e pouco divertido. Além disso, não representava os "altos e baixos" da vida acadêmica, as demandas por trabalhos, nem as interações entre colegas. 
Nas mecânicas, a cooperação estava completamente ausente, e apenas a competição estava sendo valorizada, o que não condizia com as questões teóricas da disciplina de Produção Interdisciplinar de Texto, em que buscávamos nos embasar.

Sendo assim, a fim de dar mais dinamismo e emular o desafio de concluir o trabalho de uma disciplina, incluímos a regra de que seria necessário realizar uma tarefa para considerar uma disciplina "concluída". O jogador deveria sortear uma carta e desenhar um objeto descrito na carta para ser considerado "aprovado" na disciplina. Para simplificar a prototipagem do jogo, utilizamos cartas do jogo "Imagem e Ação", que já apresentam palavras que embasam a produção de desenhos. Para realizar a qualificação, seria necessário reunir 5 dos objetos desenhados ao longo do jogo e construir uma história, como forma de reunir a "construção" que o estudante realizou ao longo das disciplinas. Na defesa de tese, ele deveria completar a "história" com os demais objetos desenhados.

Entretanto, um doutorado não é feito somente de disciplinas, qualificação e defesa. É necessário realizar outras tarefas que permitam a construção de conhecimento e a pesquisa, que configuram uma multiplicidade de caminhos diferentes que cada estudante cria a partir de suas decisões e escolhas. Inicialmente, gostaríamos de elaborar um tabuleiro que fosse construído pelos próprios jogadores ao "caminhar" pelo jogo. Entretanto, considerando que esse tipo de mecânica poderia complexificar a elaboração e aumentar o tempo de jogo, optamos por adicionar "bifurcações" no caminho, mudanças de direção, o que nos levou ao desenvolvimento do tabuleiro 4, nosso partido adotado.

Figura 2 - Terceira e quarta versões do tabuleiro

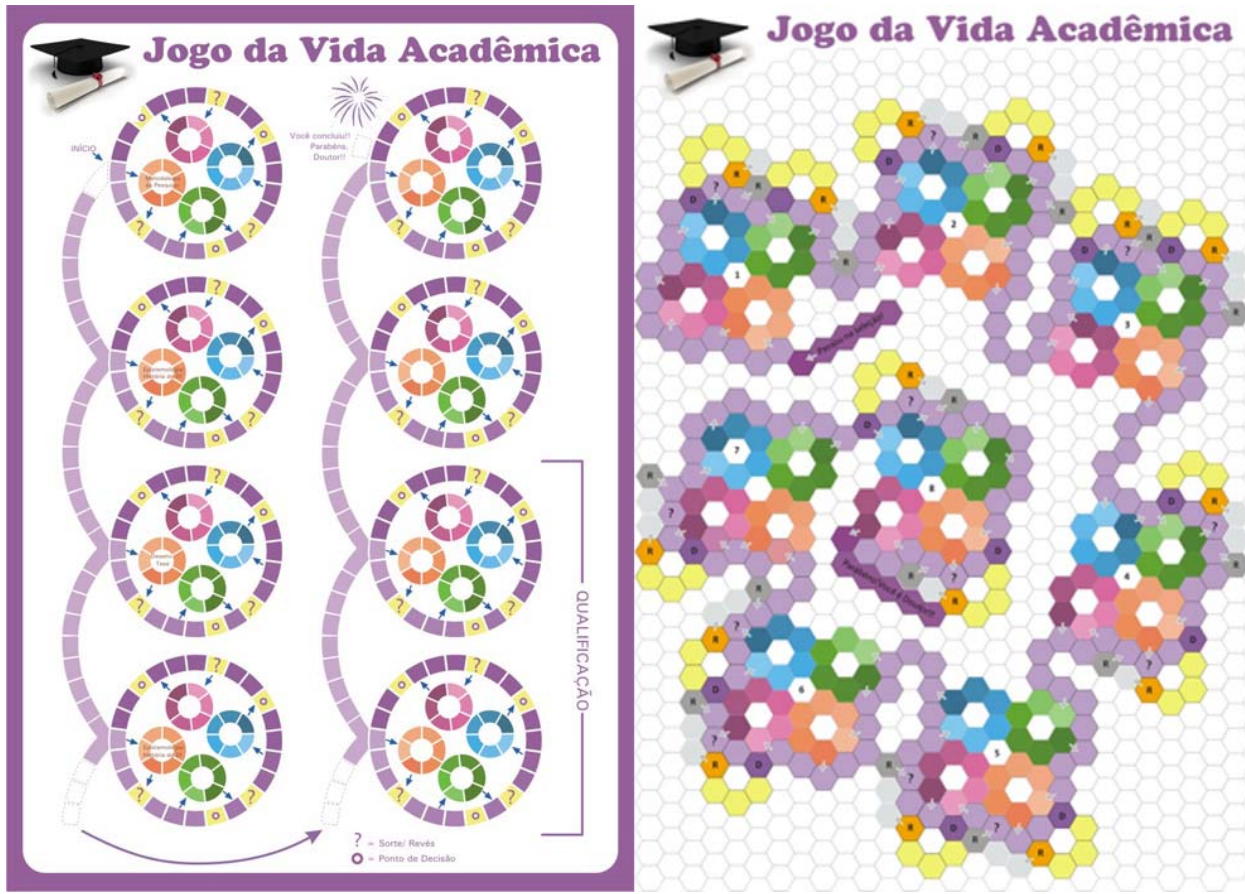

Fonte: Produzida pelos autores (2012)

A partir de uma malha hexagonal que serviu como base para a distribuição das disciplinas pelo espaço, retomamos a espiral que havíamos deixado de lado anteriormente, a fim de enfatizar 
a circularidade e os "encontros" que também podem ocorrer entre alunos que estão passando por diferentes momentos no curso. A malha hexagonal também permitiu a composição dos círculos e dos caminhos com casas de igual tamanho. Desenhamos um caminho principal que passa "ao redor" das disciplinas, e caminhos "alternativos" que desenrolam-se na parte "externa" da espiral, a fim de explorar a tomada de decisões por parte dos participantes.

Para estimular especificamente a tomada de caminhos alternativos e valorizar a dimensão do "Conhecimento", integrando-o à dinâmica de jogo, relacionamos estes dois aspectos. No ponto de tomada de decisão (casa marcada com a letra " $D$ "), o jogador deveria escolher se aceitava um desafio extra ou se seguia pelo caminho original, apenas cursando disciplinas. Porém, só nos caminhos alternativos ele conseguiria acumular os Pontos de Conhecimento e Pontos de Conhecimento Interdisciplinar, necessários para concluir o curso com sucesso.

Ao tomar uma decisão, o jogador deveria seguir pela trilha amarela, e poderia ser interpelado por situações diversas, o que o levaria a uma tomada de decisão. A forma de resolver se o resultado da decisão seria positivo - ou nem tanto - foi utilizar o dado. Se o número fosse alto (4 a 6), os jogadores leriam a primeira resposta: sinal de que o esforço foi recompensado! Se fosse baixo (1 a 3), leriam a segunda, com o resultado negativo. Porém, como acreditamos que uma atitude interdisciplinar envolve construção e desconstrução, aprender com as dificuldades e tentar um novo desafio, os jogadores nessa situação seriam apresentados a uma nova possibilidade de decisão, que mais uma vez poderia ter um "final feliz" ou nem tanto. Ao final da jogada, os jogadores saberiam o resultado dessa segunda tomada de decisão, e retornariam ao trajeto normal.

Para definir as possibilidades de decisões e resultados, construímos uma árvore de decisão. Independentemente do caminho que tomassem, em função dos dados, os jogadores sempre acumulariam pontos de conhecimento pelas experiências "vividas". A fim de trazer à discussão a cooperação, incluímos uma regra que também incentivaria, esperávamos, a participação em tarefas "extra": ao tomar uma decisão que envolvia outro colega, o jogador que toma a decisão traria o peão de quem estivesse logo atrás no tabuleiro para junto do seu, simbolizando a "parceria" e o crescimento coletivo que pode surgir a partir dela.

O objetivo final do jogo seria concluir o circuito do tabuleiro, cursando as disciplinas obrigatórias, passando pela qualificação e pela defesa de tese, e acumulando mais Pontos de Conhecimento e Pontos de Conhecimento Interdisciplinar. A ficha de "histórico escolar" foi adotada como forma de facilitar o registro das disciplinas cursadas e dos pontos obtidos.

Com o tabuleiro montado a partir do padrão hexagonal, realizamos um novo teste com dois jogadores e percebemos a necessidade de reduzir o número de cartas de decisões/resultados. Antes, havia uma carta para a primeira pergunta, uma para resposta e nova pergunta, e uma para a nova resposta, totalizando 27 cartas (a partir de 9 possibilidades de decisão). As cartas foram então reunidas da seguinte forma: a carta 1 contém a primeira pergunta, os resultados possíveis e a segunda pergunta, para o caso de o resultado não ter sido satisfatório; a carta $1 \mathrm{~A}$ contém os dois resultados possíveis para a segunda tomada de decisão, e assim por diante.

Figura 3 - Cartas de decisão e seus resultados 


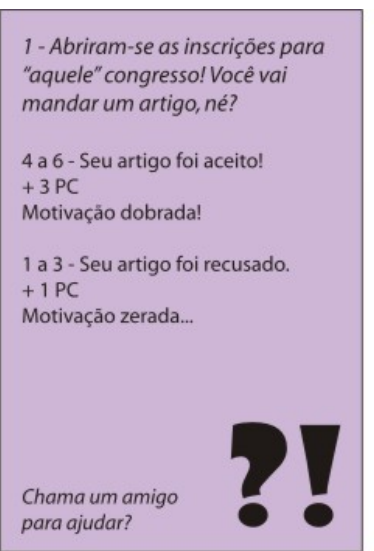

ara ajudar?

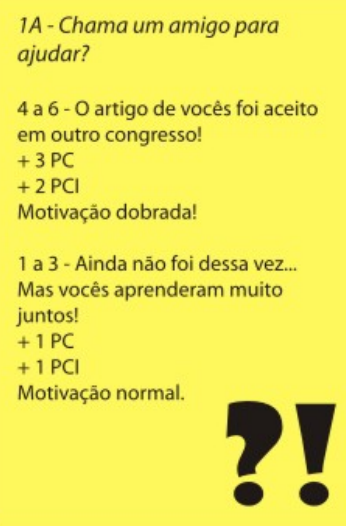

Fonte: Produzida pelos autores (2012)

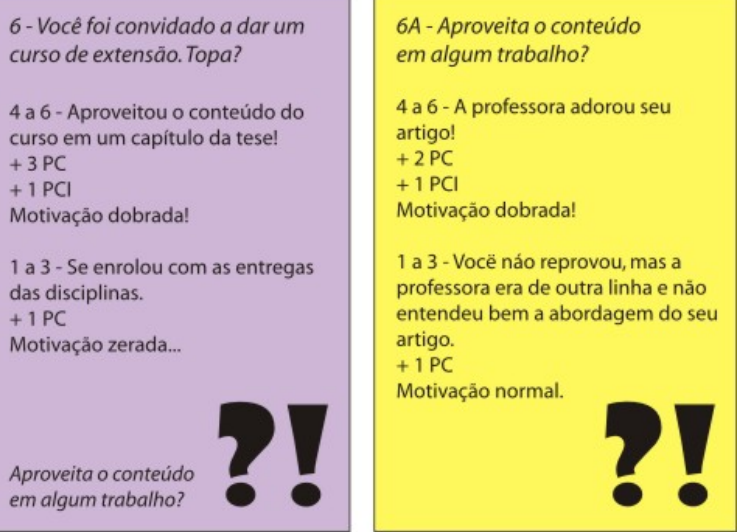

6 -Aproveita o conteúdo

artigo!

$+1 \mathrm{PC}$

Motivaçăo dobrada!

-Voce náo reprovou, mas

artigo.

Mantivemos as cartas de "Sorte ou Revés" como representação das situações que podem decorrer no curso natural da vida, e podem influenciar os caminhos que cada um leva, sem que dependa diretamente de sua intervenção.

Figura 4 - Cartas de Sorte ou Revés
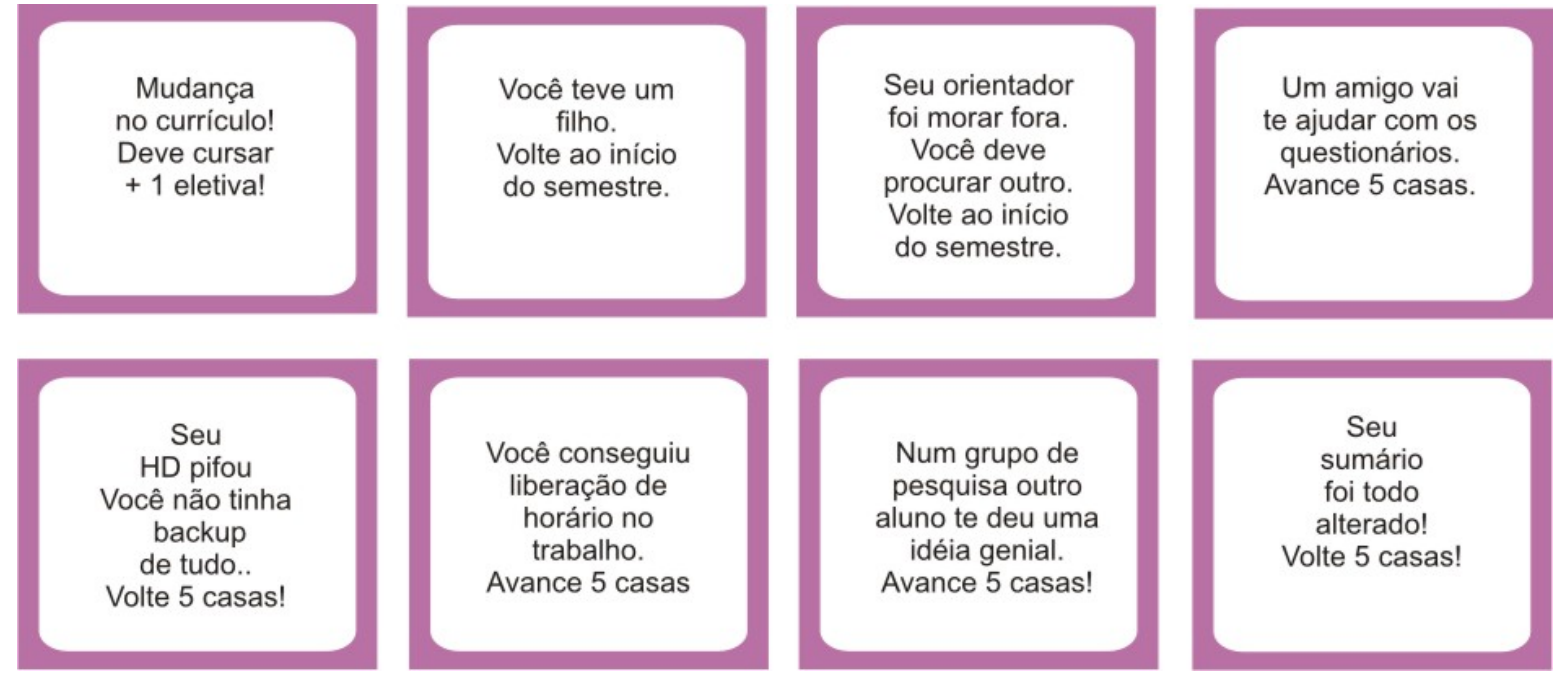

Fonte: Produzida pelos autores (2012)

Em sua versão final, o jogo contém os seguintes componentes: 1 tabuleiro; 6 peões; 6 fichas de histórico escolar; 14 cartas de sorte ou revés; 18 cartas de tomada de decisão; 2 dados, 1 ampulheta. Os jogadores sorteiam no dado a ordem de início, que representa a ordem de classificação. Cada jogador começa na primeira casa de seleção para o doutorado, e deve seguir pelo tabuleiro, tomando decisões e cumprindo as tarefas associadas a cada disciplina (a realização dos desenhos).

Cada aluno/jogador tem que cumprir 8 disciplinas, conforme a exigência do Programa de Pós-graduação em Design da PUC-Rio, e tem que passar por mais 8 círculos, que representariam o tempo dedicado à pesquisa e a orientação. Para considerar cumprida uma disciplina, o jogador tem que desenhar um objeto sorteado na carta, dentro do tempo da ampulheta. Na qualificação, o jogador deve produzir uma história com 5 objetos que tenha desenhado nas disciplinas. Na tese, 
deve terminar a história com o restante dos objetos. Em cada ponto de decisão, o jogador pode optar por trilhar um caminho que o levará a mais tomadas de decisão e à aquisição de pontos de conhecimento e de conhecimento interdisciplinar.

\section{Realizando o(s) percurso(s)}

$\mathrm{Na}$ aplicação na sala de aula, contamos com 8 jogadores, alunos da disciplina. Optamos por trabalhar com 4 duplas, a fim de colocar os jogadores para trabalhar em conjunto. Além disso, o número elevado de jogadores faria o jogo demorar muito mais que o necessário e poderia perder parte da dinâmica.

Colocamos apenas as regras essenciais no início do jogo: a constituição de duplas, a distribuição das disciplinas pelo tabuleiro, a necessidade de preencher o "histórico escolar". Essa decisão permitiu flexibilizar algumas regras que tinham sido imaginadas a princípio, e modificá-las quando necessário, para dar mais dinamismo ao jogo. A mudança começou quando verificamos a necessidade de utilizar dois dados, em vez de apenas um, para que os jogadores pudessem se movimentar mais rapidamente pelo tabuleiro e o jogo não se tornasse monótono.

Uma regra havia sido esquecida de ser anunciada no início do jogo: simbolizando o tempo de dedicação à pesquisa e orientação, além das oito disciplinas, os alunos deveriam realizar mais oito circuitos. Porém, ao ser descrita esta regra, houve uma manifestação geral do grupo, que não a aceitou por não ter sido anunciada previamente. Além disso, todos verificaram que o cumprimento dela demandaria ainda mais tempo e faria o jogo repetitivo, motivo pelo qual a regra foi ignorada.

As duplas criaram estratégias bastante diferentes, de acordo com o que o número sorteado nos dados ("a vida") Ihes permitia: uma tirou muitos números altos nos dados e optou por cursar várias disciplinas logo no início. Um jogador teve retirado seu orientador quando tinha apenas duas disciplinas cumpridas, ainda no primeiro período. Outra foi tomando decisões desde o segundo período, complementando suas disciplinas com pontos de conhecimento, pois também tirou muitas vezes números altos nos dados. A quarta dupla teve dificuldades nos dados, no início, e optou por correr à frente, cursando menos disciplinas, deixando para cursá-las em períodos posteriores. Podemos fazer um paralelo com alguém que teve pouco tempo nos primeiros períodos e deixou para cursar as disciplinas de forma mais espaçada.

A leitura das cartas de decisão ficou a cargo de uma das componentes do grupo desenvolvedor do jogo. Essa escolha teve como propósito manter o clima de descoberta, quando os jogadores soubessem o resultado de suas decisões, e teve efeito. Além disso, esse lugar de mediação facilitou o acesso do grupo às regras estabelecidas e a renegociação das mesmas. Com a dinâmica acontecendo, esse papel de "mediação" do jogo foi muitas vezes ajudado pelos próprios jogadores, que reforçavam algumas regras e interagiam, com frases como: "ainda não fiz a minha tarefa!", "qual foi o resultado da minha decisão?"; " pra onde eu vou agora?".

Pudemos perceber diversas manifestações de cooperação e envolvimento, também interduplas. Às vezes, algum peão andava mais do que o devido, mas essas pequenas casas não eram reparadas pelos colegas. Outras vezes, um peão se perdia no tabuleiro por causa de um lance de dados mais "violento". Quando isso acontecia, os colegas chamavam atenção para onde estava o peão que caiu. A dupla (e depois, o colega) que ficou mais para trás, pois havia perdido o orientador logo no primeiro período, era sempre incentivada pelo restante dos jogadores. 
A limitação das possibilidades de decisão elaboradas ficou patente quando a mesma dupla tirou duas vezes a mesma decisão: ir para um emprego público, por ter passado em um concurso, e foi necessário selecionar outra carta de decisão. Uma componente do grupo brincou: "Nossa, a gente é bom de concurso público!". Em uma futura versão do jogo, será necessário elaborar mais possibilidades de decisão.

A situação de realização de trabalhos em conjunto também trouxe outras reflexões para uma futura versão do jogo. A regra estabelecia que, ao realizar uma atividade "interdisciplinar", o jogador "carregava" junto com ele quem estivesse logo atrás, agilizando o caminho do colega. Porém, isso fazia com que se reunissem pessoas que já estavam próximas no caminhar, e outras, que estavam mais atrás, permanecessem "em desvantagem". Foi colocado que talvez fosse mais "justo" trazer quem estivesse em mais desvantagem no jogo.

O trabalho em conjunto também se manifestou de formas que não havíamos previsto, como: parceiros revezando os turnos de desenho; parceiros estabelecendo papéis: "você desenha e eu ando com o peão, pois você desenha melhor"; parceiros "salvando" a dupla, tomando a frente quando foi necessário. Por exemplo, em uma realização de tarefa, uma das jogadoras, que é aluna de intercâmbio, teve dúvidas em relação ao significado da palavra que deveria desenhar, e a outra componente da dupla logo pegou a caneta para que as duas não perdessem a disciplina, explicando em seguida o significado para a colega.

A duração do jogo ultrapassou o tempo atribuído para a "apresentação" deste enquanto seminário na disciplina de Produção Interdisciplinar de Texto. Isso fez com que as tomadas de decisão tivessem que ser rápidas e que não tenhamos conseguido concluir o jogo, ou seja, formar nenhum "doutorando", embora três das quatro duplas tenham passado pela qualificação.

A qualificação de tese como criação de uma narrativa e leitura para o restante dos jogadores constrói a metáfora de construir algo novo com aquilo tudo que a pessoa conquistou ao longo do tempo, "costurando" os conhecimentos adquiridos, além de levar tempo, pois enquanto alguém estava se preparando para a qualificação (produzindo a história), não poderia caminhar pelo tabuleiro. Esse elemento constitui-se em uma emulação enquanto processo, de maneira simplificada, e resultou ainda em um momento de descontração do grupo, pois qualquer história elaborada, por mais sem sentido que fosse, poderia ser aceita, se todos concordassem.

A constatação mais surpreendente, entretanto, foi em relação aos "percursos" trilhados. Em determinado momento, chamou-se a atenção, pois uma das jogadoras havia feito um trajeto que não era o indicado pelas setas. Percebemos que, como algumas casas se conectavam, sem entretanto configurar caminhos "previstos", e as setas indicativas das direções estavam muito claras, os caminhos acabaram por não ficar, em alguns pontos do tabuleiro, totalmente evidentes, e certas vezes os jogadores seguiam caminhos diferentes da trilha imaginada a princípio. Isso pode ter feito com que alguns jogadores tenham saído prejudicados, porém, por outro lado, realizou, sem querer, algo que havíamos imaginado no início, e não havíamos conseguido realizar (pelo menos imaginávamos não ter conseguido): que os jogadores fizessem seus próprios caminhos no tabuleiro, caminhos "nunca antes trilhados".

\section{Refletindo sobre o(s) percurso(s)}

A fim de diferenciar "brincadeira" de "jogo", Kishimoto (1994), traz três níveis elaborados por pesquisadores franceses nos quais "jogo" pode ser considerado: ' 1 o resultado de um sistema 
lingüístico que funciona dentro de um contexto social; 2 um sistema de regras e 3 um objeto'.

Aplicando essa visão ao jogo que projetamos e experimentamos, podemos verificar que ele se constituiu a partir de um sistema lingüístico, que fazia sentido dentro do contexto social, das formas e valores de vida presentes onde foi aplicado. O grupo de jogadores, composto de alunos de mestrado ou doutorado, pôde reconhecer a estrutura apresentada, os desafios colocados, e fazer um paralelo com a necessidade frequente de tomar decisões ao longo da vida acadêmica, encontrando algumas situações que já tinham vivido, ou com que se identificaram. Da mesma forma, o jogo também poderia ser aplicado e fazer sentido para jovens que estão entrando na vida acadêmica, como uma forma de familiarizar-se com os termos, idéias e construções envolvidos nessa experiência.

O jogo também representa, por meio de seu sistema de regras, uma "estrutura seqüencial que especifica sua modalidade" (KISHIMOTO, 1994, p. 108) Nesse ponto, o Jogo da Vida Acadêmica é claramente um jogo de tabuleiro, livremente inspirado no "Jogo da Vida". Este, um jogo tradicional que possibilitava basicamente dois ou três caminhos possíveis, mas guardava direta relação com o ideal de vida de casamento, trabalho, filhos e acumulação de riqueza, foi tomado realmente somente como inspiração, pois o que nos interessava era emular "regras" e mecanismos inerentes ao funcionamento do contexto que pretendíamos retratar, ressaltando aquelas que poderiam incorporar a interdisciplinaridade.

Como objeto, buscamos com o tabuleiro representar o caminho a percorrer, diferenciando os semestres, disciplinas e caminhos alternativos, e simplificando a experiência dos jogadores, ao reduzir o número de cartas e colocá-las nas mãos de um "mediador". Além disso, apresentamos uma forma de jogo que era minimamente conhecida dos jogadores, incorporando elementos de outros jogos conhecidos, como "Imagem e Ação Junior", em que é necessário desenhar imagens sorteadas em cartas para que outros colegas adivinhem, e o próprio uso de dados e peões, característicos dos jogos de tabuleiro.

Para Fromberg, podem ser tomadas como as principais características do jogo: o simbolismo, pois representa a realidade e atitudes; a significação, pois permite relacionar ou expressar experiências; o caráter voluntário ou intrinsecamente motivado, incorporando motivos e interesses; e o caráter episódico, com metas desenvolvidas espontaneamente (Fromberg, 1987 apud Kishimoto, 1994:116).

Com o Jogo da Vida Acadêmica, buscamos representar alguns caminhos possíveis e pontos de bifurcação, mas consideramos que o caso foi da emulação, mais do que da simulação. Xavier esclarece que a simulação 'aproxima o jogador do real a partir da mimética ou do quanto mais próximo é possível chegar tecnicamente de um ponto a ser imitado', abrangendo tantas possibilidades para que o jogador explore, que o jogo acabaria por se desenrolar de modo quase imprevisível (XAVIER, 2007, p. 133). No caso, partimos da emulação, 'a observação dos princípios que configuram determinada situação em sua forma mais recorrente e simples', de forma a estabelecer uma árvore de decisões (ou game tree, como apontado por Jesper Juul (2005, p. 56).

Juul afirma que o principal elemento fundante de todos os jogos são as regras, que constituem "máquinas de estado" (state machines). As regras de um jogo podem ser discutidas tanto a partir das definições dadas, embutidas no programa de um jogo eletrônico ou descritas no manual de um jogo de tabuleiro, quanto a partir do que os jogadores negociam e aprendem, desenvolvendo suas habilidades (2005, p.56). No caso de jogos analógicos, além de as regras 
poderem ser negociadas pelos jogadores, têm que ser recordadas e sustentadas por estes para que o jogo seja jogado, pois não há um programa de computador determinando as possibilidades de interação. Além disso, os "estados de jogo" são visíveis, constituídos pela configuração das peças no tabuleiro ou dos corpos no espaço (JUUL, 2005).

Em congruência com essa característica, alguns alunos concluíram que na vida real é mais difícil ser interdisciplinar, pois as parcerias são mais raras, o currículo acadêmico segue mais fechado em relação às disciplinas que devem ser cursadas. As oportunidade de congressos, artigos e cursos extra-curriculares são mais difíceis de acontecer e demandam muito mais esforço e tempo do que no jogo.

Buscamos, com as tomadas de decisão, trazer a interdisciplinaridade para o jogo como referência, como atitude 'diante de alternativas para conhecer mais e melhor; atitude de espera ante os anos consumados, atitude de reciprocidade que impele à troca, que impele ao diálogo' (Fazenda, 1995, apud Silva, 2000): ou seja, no momento de abrir-se ao desconhecido, escolhendo um caminho que poderia dar certo ou não, mas indo com a certeza de que algum aprendizado viria dali.

A interdisciplinaridade, como cooperação e diálogo, esteve presente principalmente como tema, mas aconteceu muito mais "além do tabuleiro", no que podemos entender como metajogo, ou as interações provocadas pelo jogo entre os jogadores, explicitada nas atitudes dos alunos, que andavam com os peões de outros, lembrando-os de marcar as disciplinas que já haviam cursado, mantendo em funcionamento, questionando e re-construindo as regras que haviam sido estabelecidas.

Considerando a interdisciplinaridade como intenção de atuação, o encontro mutuamente implicante de diferentes disciplinas para uma finalidade comum, os envolvidos descobriram que não se vive só de construção, mas também de desconstrução, para podermos construir novamente, em conjunto, novos sentidos e saberes. É aceitar que não há uma resposta certa, e que qualquer resposta que seja só é alcançada por meio do diálogo, de concessões e argumentações, por meio da abertura ao outro. É compreender que textos acadêmicos podem tornar-se poemas, símbolos, escrituras coletivas, imagens em movimento.

Assim, a experiência aqui discutida aponta para as múltiplas possibilidades existentes na produção acadêmica em Design e também em outras áreas. $O$ jogo coloca-se como estratégia de aprendizagem e ensino, cuja produção e aplicação promovem a reflexão acerca de diferentes conteúdos e a construção coletiva de conhecimentos. A mediação na aplicação do jogo também merece ser ressaltada como elemento importante nessa integração interdisciplinar de estratégias.

O jogo da vida real é feito de decisões e escolhas, de "caminhos que se bifurcam", como no jardim de Borges (2001). O jogo da vida acadêmica também. Possui certamente regras definidas, mas elas servem como balizadores mínimos. O caminho que cada um traça para si, por meio de suas escolhas e de seu trabalho, é imprevisível e múltiplo.

Finalmente, o jogo está em processo de revisão para ampliação das situações e temáticas representadas (a saúde mental dos estudantes, os processos de avaliação dos cursos, por exemplo, não estão presentes) e posterior aplicação em outras salas de aula, com o objetivo de promover novos momentos de discussão sobre o trajeto de um pós-graduando no Brasil e levantar possibilidades de produção de novas "regras" para esse "jardim de caminhos". 


\section{Referências}

BOGOST, lan. Persuasive Games: The Expressive Power of Videogames. The MIT Press, 2010.

BORGES, Jorge Luis. O jardim de veredas que se bifurcam. In: Ficções. São Paulo: Globo, 3a edição, p. 101-114, 2001.

CARVALHO, G. de. Gênero como ação social em Miller e Bazerman: o conceito, uma sugestão metodológica e um exemplo de aplicação. In: MEURER, J. L.; BONINI, A.; MOTTA-ROTH, D. (Eds.). Gêneros: Teorias, métodos, debates. São Paulo: Parábola, 2005. p. 130-149.

COUTO, Rita Maria de Souza \& NEVES, Maria Apparecida Campos Mamede. Movimento interdisciplinar de designers brasileiros em busca de educação avançada. 1997. Tese (Doutorado), Departamento de Educação. Pontifícia Universidade Católica do Rio de Janeiro. Rio de Janeiro, 1997.

COUTO, Rita Maria de Souza \& FARBIARZ, Jackeline Lima. Ementa da disciplina Produção Interdisciplinar de Texto. Departamento de Artes e Design - PUC-Rio, 2012. Disponível em:http://www.pedagogiadodesign.com/blogdesign/producao-interdisciplinar-de-textos/ Acesso em 05 de abril de 2018.

DAD. PPG Design. Departamento de Artes e Design - PUC-Rio, 2017. Disponível em: http://dad.puc-rio.br/pos-graduacao/sobre/. Acesso em 05 de abril de 2018.

FAZENDA, I. C. Dicionário em construção: interdisciplinaridade. São Paulo: Cortez, 2001.

FARBIARZ, Jackeline Lima. Estabelecendo a ponte: uma visão bakhtiniana de argumentação. INTERCOM - XXVI Congresso Brasileiro de Ciências da Comunicação. Sociedade Brasileira de Estudos Interdisciplinares da Comunicação, Belo Horizonte, 2003.

FULLERTON, Tracy. Game design workshop: a playcentric approach to creating innovative games. 2nd. ed. Elsevier: Massachussets, 2008.

JULL, Jesper. Half- Real. The MIT Press, 2005.

KISHIMOTO, Tizuko M. O jogo e a educação infantil. In: A modernidade, a infância e o brincar. Revista Perspectiva v. 12, n. 22, p. 105 - 208. UFSC/CED, NUP: Florianópolis, 1994.

SILVA, Gildemarks Costa. A relação educação, ciência e interdisciplinaridade. Revista brasileira Est. pedag., Brasília, v. 81, n. 199, p. 403-414, set./dez. 2000.

XAVIER, Guilherme. Imagética Eletrolúdica: A visualidade dialógica no multiverso dos jogos eletrônicos. Dissertação de Mestrado. Orientador: Prof. Luiz Antonio Luzio Coelho. 2007 